\title{
COMPOSIÇÃO E DIVERSIDADE FLORÍSTICA DE BANCO DE SEMENTES EM SOLODE ÁREA DE CAATINGA
}

\author{
J. X. MEDEIROS ${ }^{1 *}$, G. H. SILVA ${ }^{2}$, T. M. RAMOS ${ }^{1}$, R. B. OLIVEIRA' ${ }^{1}$ e A. M. F. NÓBREGA ${ }^{1}$ \\ ${ }^{1}$ Universidade Federal de Campina Grande \\ ${ }^{2}$ Universidade Federal de Lavras \\ jordaniamedeiros@hotmail.com
}

Artigo submetido em abril/2014 e aceito em dezembro/2015

DOI: $10.15628 /$ holos.2015.2098

\section{RESUMO}

O estudo avaliou a composição e riqueza florística do banco de semente em área de caatinga. Foram arranjadas sistematicamente 35 parcelas $10 \times 10 \mathrm{~m}$ e coletadas, aleatoriamente, amostras de solo com. Cada amostra foi homogeneizada e colocada para germinar em dois ambientes: pleno sol e sombra a $50 \%$. Foram encontrados 237 indivíduos, pertencentes a 13 famílias botânicas, 22 gêneros e 26 espécies. A densidade total do banco de sementes foi de 43 sementes $/ \mathrm{m}^{2}$. O tratamento sombra apresentou densidade de $33,2 \mathrm{sem} / \mathrm{m}^{2}$, com maior diversidade de indivíduos. Já o tratamento a pleno sol, obteve densidade de $9,28 \mathrm{sem} / \mathrm{m}^{2}$. O ambiente sob sombrite proporcionou maior germinação e sobrevivência inicial de plântulas.

PALAVRAS-CHAVE: Regeneração, riqueza florística, recuperação ambiental.

\section{COMPOSITION AND FLORISTIC DIVERSITY OF SEED BANK IN SOIL OF CAATINGA} AREA

\begin{abstract}
The study evaluated qualitatively and quantitatively the seed bank of an area of caatinga. 35 plots were systematically arranged $10 \times 10 \mathrm{~m}$, samples were randomly collected. Each sample was individually homogenized and placed to germinate in two environments: full sun and shade to $50 \%$. Was recorded 237 individuals belonging to 13 families and 26 species
\end{abstract}

were identified. The total density of the seed bank was approximately 43 seeds $/ \mathrm{m} 2$. The treatment with shade showed a density of $33.2 \mathrm{seed} / \mathrm{m} 2$. The treatment in full sun got density of $9.28 \mathrm{seed} / \mathrm{m} 2$. The environment under shade got more seed germination and initial survival of seedlings.

KEYWORDS: Regeneration, floristic richness, environmental recovery. 


\section{INTRODUÇÃO}

A diversidade biológica das espécies vegetacionais e suas diferentes formas de vida encobre três níveis de variabilidade: a diversidade de espécies, a diversidade genética, que se refere a variabilidade dentro do conjunto de indivíduos da mesma espécie e a diversidade ecológica, que são os diferentes ecossistemas e paisagens.

Cada paisagem é constituída por indivíduos distintos, de diferentes espécies, pertencentes a várias famílias, como exemplo disso, podemos citar as florestas, com sua variada composição florística e rica diversidade de espécies, que por sua vez é proporcionado pela interação entre o meio ambiente e os seres habitantes, através de processos que possibilitem a perpetuação e interação entre eles, como a dispersão de sementes e seu acúmulo no solo, gerando um banco de reserva da diversidade florística de uma dada área.

O conceito de banco de sementes é descrito como sendo o número de sementes que possuem viabilidade no solo em uma determinada região (ROBERTS, 1981). Para Carvalho e Favoretto (1995), o banco de sementes no solo corresponde às sementes que não germinaram, mas que permanecem no solo caso haja a necessidade de substituição da vegetação anteriormente existente devido às adversidades ocorridas em seu habitat natural e o seu sucesso depende diretamente dessa capacidade.

Assim, as sementes viáveis presentes no solo compõem o banco de sementes, que através da dormência, permanecem na superfície ou interior do solo de uma dada área, tornando-se uma das principais e mais importantes fontes de recrutamento de indivíduos de uma floresta (BUTLER; CHADZON, 1998).

Todavia, a composição do banco de sementes no solo sofre influência da dispersão tanto das espécies existentes no local, como em áreas vizinhas. Assim, para o repovoamento de uma área, a seleção natural beneficia aquelas mais adaptadas e com melhores condições de sobrevivência em relação às demais, ou seja, as que apresentaram meios mais eficientes de dispersão e rápido crescimento (YOUNG et al., 1987).

Para Caldato et al. (1996), as principais fontes de regeneração de florestas tropicais se dá através das chuvas de sementes no solo, ou seja, sementes recém dispersas, presentes no solo, que se constitui pela quantidade de sementes dormentes, através do banco de plântulas da floresta e da formação de bosques.

Dessa forma, a importância de estudos de banco de sementes no manejo da vegetação, é imprescindível para o conhecimento dos processos de regeneração natural de uma comunidade, de forma que se possa intervir corretamente na sua estrutura, destacando o conhecimento de informações indispensáveis como, o estoque de sementes no solo e a riqueza florística da área, que são importantes, por exemplo, na recuperação de uma área perturbada (DANIEL; JANKAUSKIS 1989).

Desta forma o presente trabalho objetiva conhecer a composição e a riqueza florística do banco de sementes no solo em área de Caatinga e contribuir como subsídio para estudos futuros sobre a diversidade biológica em distintas áreas no Bioma. 


\section{MATERIAL E MÉTODOS}

O estudo foi realizado em área de caatinga, pertencente ao sítio Cuncas, no município de Patos - Paraíba - Brasil, situada a $07^{\circ} 01^{\prime} 02^{\prime \prime}$ latitude sul e 370 16' 48" longitude oeste, com altitude média de 242 metros (Figura 1).

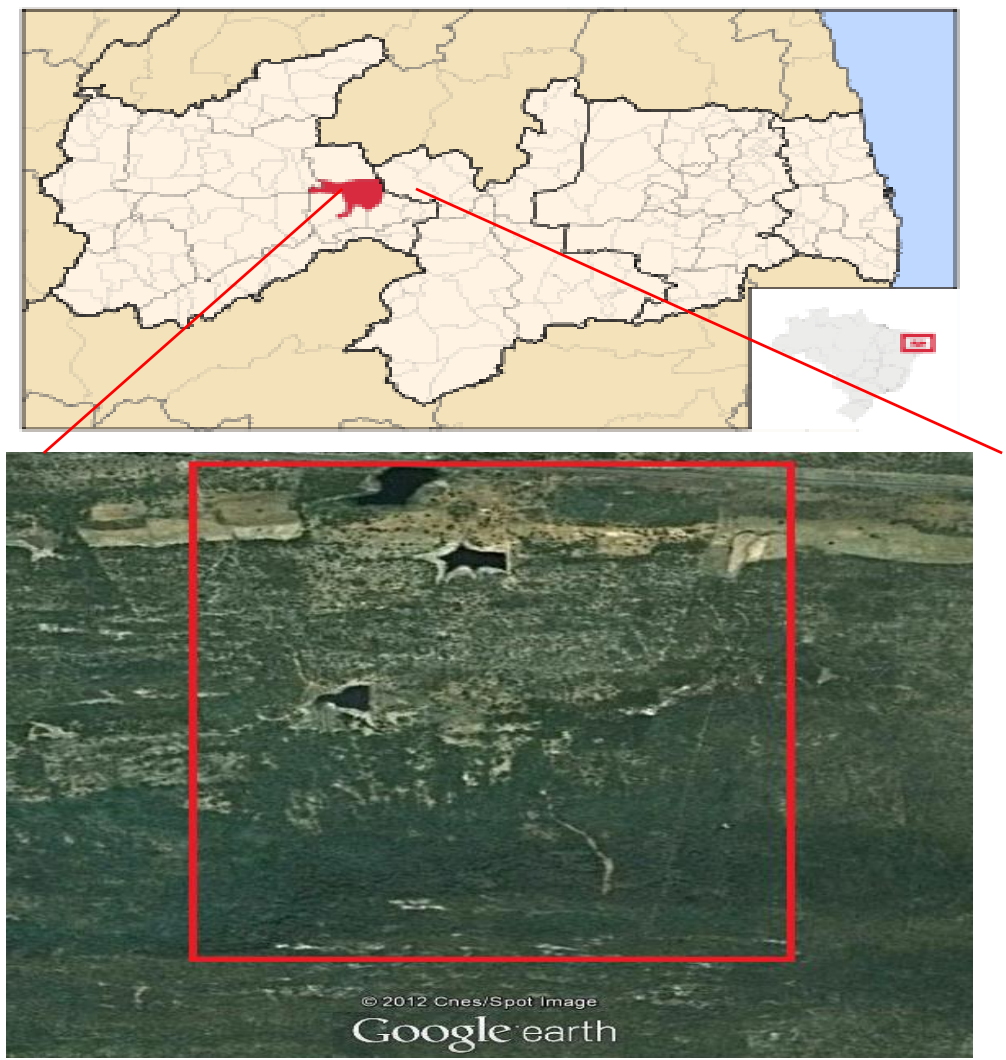

Figura 1 - Imagem da área de estudo em Patos - Paraíba - Brasil Fonte - Google Earth (earth.google.com)

A área total do sítio, com aproximadamente 300 ha, foi utilizada há cerca de 30 anos para plantio de sorgo e algodão, e desde então permaneceu em repouso para regeneração natural.

Apresenta clima do tipo Bsh (quente seco), com variações pluviométricas concentradas entre $300-800 \mathrm{~mm}$ anuais, no período chuvoso de 3 a 5 meses, principalmente de fevereiro a abril, com temperaturas médias que variam em torno de $29^{\circ} \mathrm{C}$, com aumento significativo durante o período seco.

Apresenta solos rasos, pedregosos ou arenosos com afloramentos rochosos. A vegetação é denominada como caatinga hiperxerófila, com espécies caducifólias, abundância de cactáceas espinhosas e espécies de porte baixo (ANDRADE, 1981).

Para o estudo do banco de sementes foram alocadas sistematicamente 35 parcelas de 100 $\mathrm{m}^{2}(10 \times 10 \mathrm{~m})$ em toda a área (Sítio Cuncas) e obtidas às coordenadas geográficas dos pontos de coleta com auxílio de GPS de navegação (Precisão de 2 metros), para posterior localização em campo (Figura 2). 

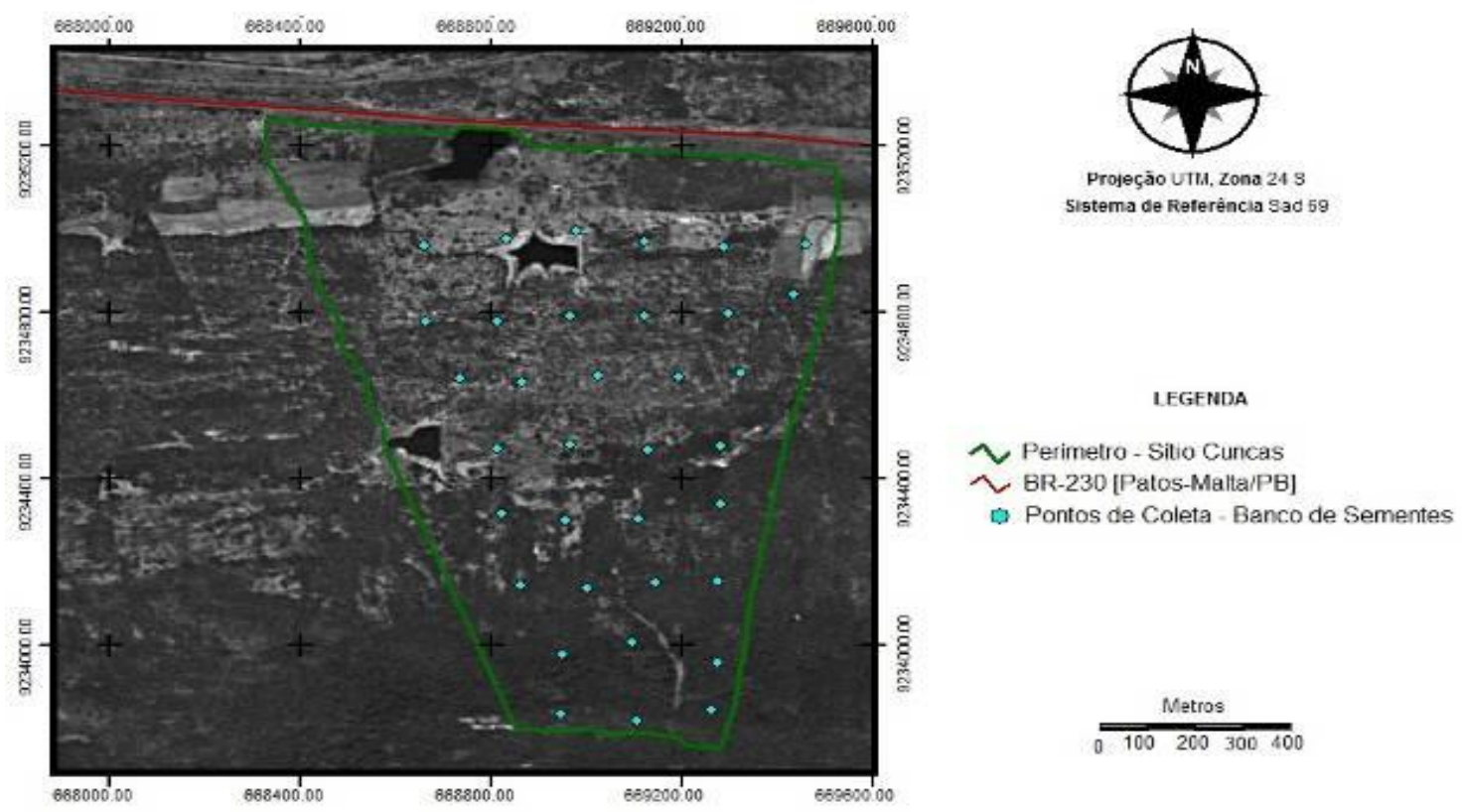

Figura 2 - Localização dos pontos de coleta do banco de sementes nos meses de maio e junho/2012, Sítio Cuncas. Fonte - MEDEIROS (2013)

Devido ausência de serrapilheira na área, foram coletadas aleatoriamente apenas amostras de solo, com o auxílio de um gabarito de madeira de $40 \mathrm{~cm} \times 40 \mathrm{~cm}\left(0,16 \mathrm{~m}^{2}\right)$ a $0-5 \mathrm{~cm}$ de profundidade em cada parcela. A profundidade desejada do solo foi medida com régua e cavada com espátula. As coletas foram realizadas nos meses de maio e junho de 2012.

Após a coleta, as amostras de solo e serrapilheira foram armazenadas em sacos plásticos pretos, etiquetados e transportados para o Viveiro Florestal da Universidade Federal de Campina Grande (UFCG)/Centro de Saúde e Tecnologia Rural (CSTR)/Unidade Acadêmica de Engenharia Florestal (UAEF), Patos - PB.

O material coletado foi homogeneizado individualmente e distribuído aleatoriamente em bandejas de alumínio $(20,0 \times 20,0 \times 5,0 \mathrm{~cm})$, de forma a não favorecer amostras, ambiente ou profundidade de coleta, dispostas em bancada a um metro da altura do solo nos dois tratamentos (sol e sombrite). A instalação do experimento foi realizada no mês de junho de 2012. A germinação se deu em dois ambientes de casa de vegetação, a pleno sol e tela com redução de luz a 50\%, com base nas recomendações descritas em Kageyama et al. (1991). No viveiro, o solo foi distribuído aleatoriamente em 35 bandejas para cada tratamento, contendo o mesmo volume de solo cada, totalizando 70 bandejas.

O volume aproximado de solo em cada bandeja foi de aproximadamente $2 \mathrm{Kg}$. Nas oito primeiras semanas do experimento, as irrigações foram realizadas duas vezes em dias quentes e uma vez em dias nublados e com temperaturas mais amenas, tendo em vista o clima característico da nossa região. A aleatorização das bandejas foi realizada duas vezes durante o período de observação (julho e outubro de 2012), para que as variações nas condições ambientais não influenciassem na germinação.

A avaliação das plântulas emergidas foi realizada quando as mesmas apresentaram estruturas morfológicas que facilitaram seu a identificação das espécies, depois quantificadas e registradas em ficha de campo, após identificação as mesmas foram retiradas das bandejas para não influenciar e/ou interferir na germinação de novos indivíduos. A contagem das plântulas 
emergidas foi realizada durante os seis meses (junho a novembro de 2012), em intervalos de sete dias, observando ausência ou não de novos indivíduos no banco.

Para auxiliar na identificação das plântulas, foram utilizadas literatura especializada, ajuda de taxonomista do CSTR, comparação com exsicatas depositadas no herbário do CSTR, além de bibliografias publicadas na área. Foram encontrados indivíduos de representantes das formas: Árvore (vegetal lenhoso com altura igual ou superior a cinco metros), Arbusto (vegetal lenhoso menor que cinco metros de altura, ramificando-se na base) e Herbácea (vegetal não lenhoso, incluindo Poaceas).

Para cada espécie presente no banco de sementes, foram calculadas a frequência, abundância relativa, valor de importância (VI) e os índices de diversidade de Shannon-Weaver $\left(\mathrm{H}^{\prime}\right)$.O índice de Shannon foi calculado com base no número de indivíduos de cada espécie e no total de indivíduos amostrados (FELFILI et al., 2003).

O Índice de Equabilidade de Pielou (J) também foi avaliado, conforme Caldato et al. (1996). O referido índice varia de 0 a 1, indicando que o máximo valor obtido, acarretará em uma maior diversidade de espécies na área em relação ao número de indivíduos amostrados.

Foi aplicado o teste qui-quadrado para comparar a influência exercida pelo ambiente quanto ao número de indivíduos, espécies e famílias presentes em cada tratamento, $\chi^{2}$ (quiquadrado) $\chi^{2}=n\left(\sum x^{2} / N\right)-N$ e nível de significância a 5\% (SOARES et al., 1991).

\section{RESULTADOS E DISCUSSÃO}

O total de sementes germinadas durante os seis meses de estudo nos dois ambientes (pleno sol e sombra) foi de 237 indivíduos, pertencentes a 13 famílias botânicas, 22 gêneros e 26 espécies. Destas, 24 espécies foram identificadas e duas não identificadas (Tabela 1).

Tabela 1: Relação das espécies arbóreas, arbustivas e herbáceas presentes no banco de sementes no sítio Cuncas, município de Patos - PB.

\begin{tabular}{|c|c|c|c|c|}
\hline Espécie & Nome popular & Família & Hábito & $\mathrm{Ni}$ \\
\hline Aristida pallensCav. & barba-de-bode & Poaceae & Herbáceo & 119 \\
\hline Amaranthus viridis $L$. & bredo-do-tabuleiro & Amaranthaceae & Herbáceo & 26 \\
\hline Senna obtusifolia L. & mata-pasto & Fabaceae & Arbusto & 20 \\
\hline Mimosa tenuiflora (Mart.) Benth. & jurema-preta & Fabaceae & Arbóreo & 14 \\
\hline Wissadula sp. & malva-branca & Malvaceae & Arbusto & 08 \\
\hline Macroptilium lathyroides (L.) Urb & feijão-de-rolinha & Fabaceae & Arbusto & 06 \\
\hline Jaqumontia asarifolia L. B. Smith & amarra-cachorro & Convolvulaceae & Herbáceo & 06 \\
\hline Aristida setifoliaKunth. & capim-panasco & Poaceae & Herbáceo & 04 \\
\hline Cleoma spinosa Jacq. & mussambê & Capparidaceae & Arbusto & 04 \\
\hline Arachis pusilla Benth & amendoim-do-mato & Fabaceae & Herbáceo & 04 \\
\hline Anadenanthera colubrina (Vell.) Brenan & angico & Fabaceae & Arbóreo & 03 \\
\hline Eleusine indicata (L.) Gaertn. & capim-pé-de-galinha & Poaceae & Herbáceo & 03 \\
\hline Mimosa pudica $\mathrm{L}$. & dormideira & Fabaceae & Arbusto & 03 \\
\hline Piptadenia stipulacea (Benth.) Ducke & jurema-branca & Fabaceae & Arbóreo & 02 \\
\hline Hyptissu aveolen(L.) Point & alfazema-brava & Lamiaceae & Arbusto & 02 \\
\hline Croton campestris St. Hil. & velame-de-baixio & Euphorbiaceae & Arbusto & 02 \\
\hline Sida spinosa (L.) & relógio & Malvaceae & Arbusto & 02 \\
\hline Jacquemontia sphaerostigmaCav. Rusby & batata-azul & Convolvulaceae & Herbáceo & 01 \\
\hline Desmanthus virgatusL. (Willd.) & jureminha & Fabaceae & Arbusto & 01 \\
\hline Polygonumhy dropiper $\mathrm{L}$. & pimenta d'água & Polygonaceae & Herbáceo & 01 \\
\hline
\end{tabular}




\begin{tabular}{|c|c|c|c|c|}
\hline Sida sp. & vassourinha & Malvaceae & Arbusto & 01 \\
\hline Amaranthus blitum L. & bredo-de-burro & Amaranthaceae & Herbáceo & 01 \\
\hline Physalis angulataL. & canapu & Solanaceae & Herbáceo & 01 \\
\hline Acanthos permumhispidum D.C. & espinho-de-cigano & Asteraceae & Herbáceo & 01 \\
\hline Commelina erecta $\mathrm{L}$. & sapata-de-santa luzia & Commelinaceae & Herbáceo & 01 \\
\hline Cucumis anguria $L$. & maxixe & Cucurbitaceae & Herbáceo & 01 \\
\hline
\end{tabular}

A densidade encontrada no presente estudo foi de $42,3 \mathrm{sem} / \mathrm{m}^{2}$ (423.000 sem/ha). Observa-se que a densidade de indivíduos e a riqueza de espécies arbóreas encontradas no solo da área de estudo foram maiores quando comparadas com outros trabalhos (ROIZMAN, 1993; BAIDER, 1994; SIQUEIRA, 2002).

No período de realização desta pesquisa, a reduzida precipitação e a má distribuição das chuvas provavelmente afetou a produção de sementes de algumas espécies, acarretando em baixa abundância e riqueza florística do banco de sementes na área.

Trovão e Carvalho (2006) observaram uma maior densidade de sementes em área de caatinga em diferentes estádios de sucessão. As autoras identificaram maior número de sementes germinadas, consequentemente maior densidade, na profundidade de coleta também adotada neste trabalho, onde uma maior tendência de indivíduos herbáceos foi constatada. Entre as espécies encontradas no banco, as formas de vida predominantes foram as herbáceas, com 13 espécies e 169 indivíduos, seguida das arbustivas, 10 espécies e 49 indivíduos e arbóreas representadas por três espécies e 19 indivíduos.

Em áreas degradadas, a predominância de sementes de espécies herbáceas, ocorre com maior frequência nos bancos de sementes, em decorrência dos distúrbios intensos, ocorridos no passado (BUTLER e CHAZDON, 1998; BAIDER et al., 2001; ARAÚJO et al., 2004).

A reduzida contribuição de espécies lenhosas no banco de sementes, também foram relatados por Chacon Filho, (2007), Mamede (2003) e Baider (1994), no qual, houve o predomínio de espécies herbáceas nos trabalhos desenvolvidos com banco de sementes, independente do ambiente. A germinação de grande quantidade destes indivíduos no solo se atribui à facilidade de dispersão e a entrada e incorporação destas sementes ao solo, ao seu tamanho reduzido, baixa predação, suportam condições adversas, sobrevivem tanto em ambientes secos como úmidos, são rústicas e pouco exigentes quanto ás condições edáficas (SIQUEIRA, 2002; VINHA, 2008).

Dos 237 indivíduos presentes no banco de sementes, 8\% corresponderam as espécies arbóreas (Mimosa tenuiflora, Anadenanthera colubrina e Piptadenia stipulacea). Enquanto que as arbustivas representaram 49 indivíduos, correspondendo $20,7 \%$ do total. Destas, destacaram-se Senna obtusifolia e Wissadula sp. As herbáceas com 169 (71,3\% de indivíduos) destacando-se Aristida pallense e Amaranthus Viridis.

As famílias botânicas com maior riqueza florística foram: Fabaceae, com oito espécies, Poaceae e Asteraceae, ambas com três espécies, as demais contribuíram com duas a três espécies. Com relação ao número de indivíduos, Poaceae (126 indivíduos), e Fabaceae (53 indivíduos) destacaram-se em relação às demais (Figura 3). 


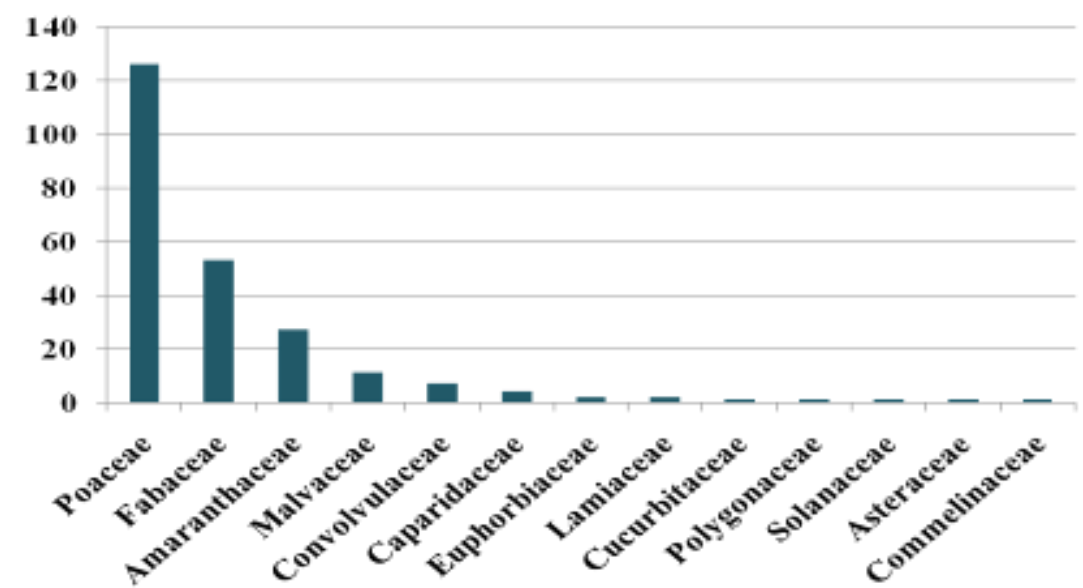

Figura 3 - Número de indivíduos e respectivas famílias amostradas no banco de sementes do Sítio Cuncas, Patos PB.

A baixa riqueza e diversidade florística no banco de sementes na Caatinga, se atribui a vários fatores, como a predação, estado de dormência das sementes, a baixa precipitação, ausência de polinizadores, dispersores, intervenções agrícolas, exploração irracional e desordenada dos recursos florestais e o estado de conservação da área. Tais fatores provavelmente influenciaram em redução na germinação das sementes, bem como as altas temperaturas aliadas a baixa precipitação acarretou na inviabilidade destas no solo, reduzindo assim sua frequência (estoque). Estes fatores possivelmente contribuíram para estes resultados.

Dentre as espécies amostradas, 11 foram comuns nos dois tratamentos - pleno sol e sombreamento: jurema preta (Mimosa tenuiflora), mussambê (Cleoma spinosa), mata pasto (Senna obtusifolia) alfazema brava (Hyptissu aveolen), amarra cachorro (Jaqumontia asarifolia), amendoim do mato (Arachi spusilla), barba de bode (Aristida pallens), bredo do tabuleiro (Amaranthus Viridis),capim pé-de-galinha (Eleusine indicata), feijão de rolinha (Macroptilium lathyroides), jurema preta (Mimosa tenuiflora) e malva branca (Wissadula sp.) (Tabela 2).

Tabela 2: Espécies comuns presentes no banco de sementes nos tratamentos estudados.

\begin{tabular}{l|cc}
\hline \multicolumn{1}{c|}{ Espécies } & Pleno sol & Sombrite \\
\hline Aristida pallens & $\mathrm{X}$ & $\mathrm{X}$ \\
Jacquemontias phaerostigma & & $\mathrm{X}$ \\
Macroptilium lathyroides & $\mathrm{X}$ & $\mathrm{X}$ \\
Aristida setifolia & & $\mathrm{X}$ \\
Senna obtusifolia & $\mathrm{X}$ & $\mathrm{X}$ \\
Hyptissu aveolen & $\mathrm{X}$ & $\mathrm{X}$ \\
Cleoma spinosa & $\mathrm{X}$ & $\mathrm{X}$ \\
Mimosa tenuiflora & $\mathrm{X}$ & $\mathrm{X}$ \\
Eleusine indicata & $\mathrm{X}$ & $\mathrm{X}$ \\
Mimosa pudica & & $\mathrm{X}$ \\
Jaqumontia asarifolia & $\mathrm{X}$ & $\mathrm{X}$ \\
Desmanthus virgatus & & $\mathrm{X}$ \\
Polygonumhy dropiper & $\mathrm{X}$ & \\
Arachis pusilla & $\mathrm{X}$ & $\mathrm{X}$ \\
Wissadula sp. & $\mathrm{X}$ & $\mathrm{X}$ \\
Amaranthus viridis & $\mathrm{X}$ & $\mathrm{X}$ \\
\hline
\end{tabular}




\begin{tabular}{l|ll}
\hline Croton campestris & & $\mathrm{X}$ \\
Sida spinosa & & $\mathrm{X}$ \\
Sida Sp. & & $\mathrm{X}$ \\
Amaranthus blitum & & $\mathrm{X}$ \\
Physalis angulata & $\mathrm{X}$ & \\
Acanthos permumhispidum & $\mathrm{X}$ & \\
Commelina erecta & & $\mathrm{X}$ \\
Anadenanthera colubrina & & $\mathrm{X}$ \\
Piptadenia stipulacea & $\mathrm{X}$ & \\
Cucumis anguria & & \\
\hline
\end{tabular}

Os resultados obtidos da germinação das amostras do banco de sementes, coletadas e colocadas sob duas condições de luminosidade, estão expostos nas Tabelas 1 e 2, o que demonstra o número de sementes germinadas sob sombrite ser superior ao pleno sol.

Fato este que, provavelmente, ocorreu devido à maior umidade neste ambiente, tornandoo propício à germinação das sementes contidas nas amostras de solo, uma vez que a água é o vetor desencadeante para este processo.

Resultado semelhante foi obtido por Chacon Filho (2007), no qual o maior número de indivíduos germinados foi obtido no tratamento sombra. Após a aplicação do teste de $\chi^{2}$ (quiquadrado) ao nível de $5 \%$ de significância, constatou-se que a relação entre a superioridade de indivíduos germinados sob redução de luz, está diretamente relacionada ao fator ambiente $\left(\chi^{2}=75,4 ; g \mid=1\right)$.

Contudo, quando analisado a frequência do número de famílias e de espécies entre os tratamentos, o teste demonstrou-se não significativo. O fator ambiente foi determinante na germinação de novos indivíduos, favorecidos com a sombra, fato este que pode estar relacionado, por exemplo, com uma menor perda de água e consequente aumento de umidade.

Por outro lado, o ambiente a pleno sol apresentou quantidade semelhante de espécies e foi superior em número de famílias, indicando que estes dois índices analisados independem do ambiente, o qual para a região semiárida se apresenta como um fato positivo.

Nas tabelas 3 e 4 encontram-se os cálculos de abundância, frequência relativas e o índice de importância do banco de sementes no solo (IVB).

Tabela 3: Número de indivíduos, abundância, frequência relativa, e índice de valor de importância do banco de sementes no solo para o tratamento Sombrite a $50 \%$ de redução de luz em área de caatinga, Patos - PB.

\begin{tabular}{lllll}
\hline \multicolumn{5}{c}{ Sombrite (50\%) } \\
\hline Espécies & $\mathbf{N}^{\circ}$ & Ab\% & Fr\% & IVB \\
\hline Aristida pallens & 108 & 58,70 & 17,39 & 76,09 \\
Senna obtusifolia & 10 & 5,43 & 15,22 & 20,65 \\
Amaranthus viridis & 25 & 13,59 & 2,17 & 15,76 \\
Jaquimontia asarifolia & 4 & 2,17 & 8,70 & 10,87 \\
Macroptilium lathyroides & 5 & 2,72 & 6,52 & 9,24 \\
Aristida setifolia & 4 & 2,17 & 6,52 & 8,70 \\
Mimosa Tenuiflora & 4 & 2,17 & 6,52 & 8,70 \\
Arachis pusilla & 4 & 2,17 & 4,35 & 6,52 \\
Anadenanthera colubrina & 3 & 1,63 & 4,35 & 5,98
\end{tabular}




\begin{tabular}{lllll} 
Sida spinosa & 2 & 1,09 & 4,35 & 5,43 \\
Cleoma spinosa & 3 & 1,63 & 4,35 & 5,98 \\
Mimosa pudica & 3 & 1,63 & 2,17 & 3,80 \\
Croton campestris & 2 & 1,09 & 2,17 & 3,26 \\
Piptadenia stipulacea & 2 & 1,08 & 2,13 & 3,20 \\
Hyptissu aveolen & 1 & 0,54 & 2,17 & 2,72 \\
Jacquemontia sphaerostigma & 1 & 0,54 & 2,17 & 2,72 \\
Eleusine indicata & 1 & 0,54 & 2,17 & 2,72 \\
Desmanthus virgatus & 1 & 0,54 & 2,17 & 2,72 \\
Wissidula sp. & 1 & 0,54 & 2,17 & 2,72 \\
Sida sp. & 1 & 0,54 & 2,17 & 2,72 \\
Amaranthus blitum & 1 & 0,54 & 2,17 & 2,72 \\
\hline TOTAL & 186 & $100 \%$ & $100 \%$ & - \\
\hline
\end{tabular}

№ = número de indivíduos; Fr\% = Frequência relativa; $\mathrm{Ab} \%$ = abundância relativa; IVB = índice de valor de importância do banco de sementes no solo.

No tratamento sombra, as espécies que obtiveram maior IVB foram Senna obtusifolia e Aristidapallens, espécies arbustiva e herbácea, indicando que o tratamento sombra propicia melhores condições para germinação destas espécies.

Araújo et al. (2001) ressaltam que, a predominância de uma forma de vida em um ecossistema, não depende apenas da área, mas também da microrregião, pois em uma área antes perturbada, ou seja, onde o ecossistema foi degradado, há uma forte influência na predominância de espécies invasoras poaceas, arbustivas e herbáceas.

Tabela 4: Número de indivíduos, abundância, frequência relativa, e índice de valor de importância do banco de sementes no solo para o tratamento a pleno sol em área de caatinga, Patos - PB.

\begin{tabular}{|c|c|c|c|c|}
\hline \multicolumn{5}{|c|}{ Tratamento 2 - Pleno sol } \\
\hline Espécies & $\mathbf{N}^{\circ}$ & $A b \%$ & Fr\% & IVB \\
\hline Mimosa tenuiflora & 10 & 19,61 & 26,67 & 46,27 \\
\hline Senna obtusifolia & 10 & 19,61 & 20,00 & 39,61 \\
\hline Aristida pallens & 11 & 21,57 & 6,67 & 28,24 \\
\hline Wissidula sp. & 7 & 13,73 & 6,67 & 20,39 \\
\hline Jaqumontia asarifolia & 2 & 3,92 & 6,67 & 10,59 \\
\hline Eleusine indicata & 2 & 3,92 & 3,33 & 7,25 \\
\hline Macroptilium lathyroides & 1 & 1,96 & 3,33 & 5,29 \\
\hline Arachis pusilla & 1 & 1,96 & 3,33 & 5,29 \\
\hline Amaranthus viridis & 1 & 1,96 & 3,33 & 5,29 \\
\hline Polygonum hydropiper & 1 & 1,96 & 3,33 & 5,29 \\
\hline Cleoma spinosa & 1 & 1,96 & 3,33 & 5,29 \\
\hline Physalis angulata & 1 & 1,96 & 3,33 & 5,29 \\
\hline Acanthos permumhispidum & 1 & 1,96 & 3,33 & 5,29 \\
\hline Commelina erecta & 1 & 1,96 & 3,33 & 5,29 \\
\hline Hyptissu aveolen & 1 & 1,96 & 3,33 & 5,29 \\
\hline Cucumis anguria & 1 & 1,92 & 3,23 & 5,15 \\
\hline TOTAL & 52 & $100 \%$ & $100 \%$ & - \\
\hline
\end{tabular}

№ = número de indivíduos; Fr\% = Frequência relativa; $\mathrm{Ab} \%$ = abundância relativa; IVB = índice de valor de importância do banco de sementes no solo.

Essas características inerentes as espécies arbustivas e herbáceas, propiciaram maior resistência delas às condições semiáridas, uma vez que permaneceram por mais tempo viáveis no solo, devido à grande quantidade de sementes dispersas pela planta mãe e não serem tão atrativas aos predadores. 
O tratamento sol apresentou $\left(\mathrm{H}^{\prime}=0,97\right.$ e $\left.\mathrm{J}=0,85\right)$ destacando-se a presença da espécie arbórea pioneira Mimosa tenuiflora, com maior número de indivíduos germinados. Já o tratamento sombra à $50 \%$ de redução de luz resultou em $\left(H^{\prime}=1,27\right.$ e J = 0,98), com destaque para a germinação de herbáceas, com 8 espécies. Resultado semelhante foi obtido por Chacon Filho (2007) em trabalho realizado na caatinga, no qual, os maiores índices de diversidade foram obtidos no tratamento sombra.

Essa diferença entre germinação no número de determinadas espécies pode ser entendido pela baixa equitabilidade, no qual poucas espécies são responsáveis pela maioria dos indivíduos no banco.

A espécie Mimosa tenuiflora apresentou maior valor de importância em relação às demais espécies no tratamento sol, indicando maior adaptabilidade a área. Gorresio-Roizman (1993) Apud Caldato et al. (1996) encontraram índices totais em diferentes profundidades e do folhedo de $H^{\prime}=$ 1,65 e J = 0,57 para as espécies arbóreas. Para a autora, a diversidade do banco indica baixa riqueza e equabilidade, refletindo pouca equitatividade na distribuição dos indivíduos.

\section{CONCLUSÕES}

O banco de sementes do solo avaliado caracterizou-se pela reduzida presença de espécies arbóreas, com tendência predominante do estrato herbáceo, provavelmente decorrente do estado de conservação da área, que antes fora utilizado para agricultura, reduzindo a diversidade florística.

O ambiente com sombra proporcionou maior germinação dos indivíduos presentes no banco de sementes do solo, denotando a fragilidade das sementes em relação à exposição excessiva ao sol, principalmente por estas se encontrarem em ambiente semiárido, solo parcialmente descoberto, não encontrando condições de sobrevivência as condições adversas do meio.

As espécies Aristida pallens (herbácea) e Mimosa tenuiflora (arbórea) apresentam valores de frequência e importância superiores em relação às demais espécies encontradas.

\section{REFERÊNCIAS}

1. ABDULHADI, R.;LAMB, D. Soil seed stores in a rainforest succession, Proc. Ecol. Soc. Aust., v. 15, p. 81-87, 1987.

2. ARAÚJO, M. M.; LONGHI, S. J.; BARROS, P. L. C.; BRENA, D. A. Caracterização da chuva de sementes, banco de sementes do solo e banco de plântulas em floresta estacional decidual ripária, Cachoeira do Sul, RS, Brasil. Scientia Forestalis, Piracicaba, n. 66, p. 128-141, 2004.

3. BAIDER, C., 1994. O banco de sementes e de plântulas na sucessão da Mata Atlântica. (Dissertação de Mestrado), Instituto de Biociências, Universidade de São Paulo, São Paulo. 1994.

4. BAIDER, C., TABARELLI, M. \& MANTOVANI, W. 2001. The soil seed bank during Atlantic Forest regeneration in southeast Brazil. Revista Brasileira de Biologia, 61:35-44. 2001.

5. BAIDER, C.; TABARELLI, M.; MANTOVANI, W. O banco de sementes de um trecho de uma 
floresta atlântica Montana (São Paulo-Brasil) p. Revista Brasileira de Biologia, São Carlos, v.59, n.2, p.319-328, 1999.

6. BASKIN, C. C.; BASKIN, J. M. Physiology of dormancy and germination in relation to seed bank ecology. In: LECK, M. A. Ecology of soil seed banks, Academic Press, San Diego, p. 3-7. 461p. 1989.

7. BUTLER, B. J.; CHAZDON, R. L. 1998. Species richness, spatial variation, and abundance of soil seed bank of a secondary tropical rain forest. Biotropica, 30:214-222.

8. CALDATO, S. L.; FLOSS, A. P.; DA CRORCE, D. M.; LONGHI, S. J. Estudo da regeneração natural, banco de sementes e Chuva de sementes na reserva genética Florestal de caçador, SC. Ciência Florestal, Santa Maria, v. 6, n.1, p.27-38, 1996.

9. CARVALHO, J. O.P. Manejo de regeneração natural de espécies florestais. Belém: EMBRAPA - CPATU, 1984. 22 p.

10. CARVALHO, P. C. F.; FAVORETTO, V. 1995. Impacto das reservas de sementes no solo sobre a dinâmica populacional das pastagens. Informativo Abrates, v.5, n.1, p. 87-108.

11. CHACON FILHO, H. M. Dinâmica do banco de sementes em duas localidades da região semiárida paraibana. Monografia (Graduação) Curso de Engenharia Florestal. CSTR/UFCG, Patos-PB, 2007 30p.

12. DANIEL, O.; JANKAUSKIS, J. Avaliação de metodologia para o estudo do estoque de sementes do solo. IPEF, Piracicaba, v.41-42, p.18-26, 1989.

13. FELFILI, J. M.; REZENDE, R. P. Conceitos e métodos em fitossociologia. Comunicações Técnicas Florestais, Brasília (Universidade Federal de Brasília), v.5, n.1, 2003.

14. FINOL, U. H. Nuevos parámetros a considerarse en el análisis estrutural de las selvas virgens tropicales. Rev. For. Venez., Merida, v. 14, n.21, p.29-42, 1971.

15. GOREEESIO-ROIZMAN, L. G. Fitossociologia e dinâmica do banco de sementes de populações arbóreas de floresta secundária em São Paulo, SP. São Paulo, 1993. 184 p. Dissertação (Mestrado em Ecologia) - Setor de Ecologia, Universidade de São Paulo. 1993.

16. KAGEYAMA, P.Y.; VIANA, V.M. Tecnologia de sementes e grupos ecológicos de espécies arbóreas tropicais. In: SIMPÓSIO BRASILEIRO DE TECNOLOGIA DE SEMENTES FLORESTAIS. Atibaia. Anais. Atibaia, 1989. p.197-215. 1989.

17. MAMEDE, M. A. 2003. Efeito do manejo agrícola tradicional sobre o banco de sementes do solo em uma área de caatinga, município de Sobral, CE. 68 p. Dissertação (Mestrado em Desenvolvimento e Meio Ambiente). Universidade Federal do Ceará, CE.

18. ROBERTS, H. A. 1981. Seed banks in the soil. Advances in Applied Biology, Cambridge, Academic Press, v.6, 55 p.

19. SIQUEIRA, L. P. de. Monitoramento de áreas restauradas no interior do Estado de São Paulo, Brasil. 2002. 116 p. Dissertação (Mestrado em Conservação e Ecossistemas Florestais) - Escola Superior de Agricultura Luiz de Queiroz, Piracicaba.

20. SOARES, J. F.; FARIAS, A. A.; CESAR, C.C. 1991. Introdução à Estatística. Editora Guanabara Koogan S. A. Rio de Janeiro. R.J. 378p.

21. TROVÃO, D. M. B. M.; CARVALHO, E. C. D. Avaliação do banco de sementes em fragmentos de caatinga em diferentes estágios de sucessão. In: 58a REUNIÃO ANUAL DA SBPC, Julho/2006, 
Florianópolis. Anais... Santa Catarina, 2006.

22. VINHA, D. Banco de sementes em áreas com diferentes graus de perturbação no Parque Estadual das Fontes do Ipiranga, em São Paulo, SP. 2008. 105 f. Tese (Mestrado em Botânica) - Instituto de Botânica de São Paulo, São Paulo. 2008.

23. YOUNG, K. R.; EWEL, J. J.; BROWN, B. J. Seed dynamics during forest succession in Costa Rica, Vegetatio, v.71, p. 157-173, 1987. 